\title{
AVALIAÇÃO DE ÍNDICES DE FIRMEZA PARA ABACAXI MINIMAMENTE PROCESSADO EM FATIAS TRATADAS COM SOLUÇÕES DE SAIS DE CÁLCIO ${ }^{1}$
}

\author{
MARISA DE P. EDUARDO ${ }^{2}$, BENEDITO C. BENEDETTI ${ }^{3}$, ANTONIO C. O. FERRAZ ${ }^{4}$
}

RESUMO: Produtos minimamente processados estão prontos para o consumo imediato e devem apresentar qualidade sensorial semelhante à do produto fresco. Embora a maioria dos estudos seja com hortaliças, constata-se o grande potencial de comercialização de frutas minimamente processadas, principalmente aquelas que oferecem alguma dificuldade para a comercialização ou até mesmo para o preparo, sendo o abacaxi um ótimo exemplo disso. O objetivo deste trabalho foi avaliar o efeito de diferentes sais de cálcio (cloreto, sulfato e lactato), nas concentrações de $1 \%$ e $3 \%$, utilizando-se de medidas de $\mathrm{pH}$, sólidos solúveis totais e da firmeza, em fatias de abacaxi minimamente processadas. Dois tipos de ponteiras de penetração (cilíndrica e anel vazador) e três índices de firmeza foram utilizados para mensurar a textura, visando a identificar o melhor índice. Os resultados mostraram que os tratamentos com sulfato de cálcio 3\% mantiveram o índice de firmeza das fatias em até $44,45 \%$ superior ao da testemunha. Os índices da ponteira cilíndrica, apesar de apresentarem variabilidade semelhante aos da ponteira de anel vazador, apontaram número maior de diferenças entre a testemunha e os tratamentos.

PALAVRAS-CHAVE: propriedades mecânicas, energia de deformação, vida útil, textura.

\section{FIRMNESS INDEXES EVALUATION FOR FRESH-CUT SLICED PINEAPPLE TREATED WITH CALCIUM SALTS SOLUTIONS}

\begin{abstract}
Fresh-cut sliced fruits and vegetables are ready to eat immediately and their sensorial characteristics should be similar to fresh product. Although most of the studies in this area are focused on vegetables, there is a great market potential for fresh-cut sliced fruits, mainly for those which exhibit some commercialization or preparation difficulties such as pineapple. The objective of this work was to evaluate the effect of $1 \%$ and $3 \%$ concentrations of calcium salts (chloride, sulphate and lactate) on $\mathrm{pH}$, total soluble solids and firmness values of minimally processed pineapple slices. Two types of indenters and three firmness indexes were investigated aiming to identify the best index. Results showed that calcium sulphate 3\% kept average firmness index up to $44.45 \%$ higher than the index value of the control. Even though both indenters exhibited similar variability the cylindrical one was able to point out more differences between control and treatments than the cylindrical borer indenter.
\end{abstract}

KEYWORDS: mechanical properties, deformation energy, shelf life, texture.

\section{INTRODUÇÃO}

O interesse pela conservação de frutas após a colheita tem aumentado no Brasil, nos últimos anos, em virtude de diversos fatores, tais como: grandes safras, aumento do consumo, necessidade de abastecimento permanente de frutas frescas no mercado e incremento no volume de exportações. Isso tem motivado maior preocupação com relação à preservação da qualidade da fruta e à extensão do seu período de comercialização. Entretanto, apesar do grande potencial da fruticultura, o Brasil está distante de ser um país que conserva com eficácia suas frutas após a colheita, apresentando

\footnotetext{
${ }^{1}$ Extraído da dissertação de mestrado do primeiro autor.

${ }^{2}$ Eng ${ }^{a}$ Agrônoma, Mestre Engenharia Agrícola, Rua Campos Salles, 1.818, Piracicaba - SP.

${ }^{3}$ Eng $^{\mathrm{O}}$ de Alimentos, Livre Docente, FEAGRI/UNICAMP, Caixa Postal 6011, Campinas - SP, Bolsista PQ-2 CNPq, benedeti@agr.unicamp.br

${ }^{4}$ Eng ${ }^{\mathbf{o}}$ Agrícola, Livre Docente, FEAGRI/UNICAMP, Caixa Postal 6011, Campinas - SP.

Recebido pelo Conselho Editorial em: 11-5-2006
}

Aprovado pelo Conselho Editorial em: 25-2-2008 
altos índices de perdas, devido, principalmente, ao desconhecimento da fisiologia pós-colheita e de técnicas adequadas de conservação e/ou processamento.

A oferta de hortícolas limpas, embaladas, semiprocessadas e prontas para o preparo e/ou consumo é de visível crescimento, pois atende aos desejos e às necessidades dos consumidores, os quais passam a exigir mais qualidade, praticidade e lançamento de novos produtos. No entanto, o consumo de produtos minimamente processados (MP) está localizado nos grandes centros urbanos, principalmente pelas classes sociais A e B (70\% do consumo), dado seu elevado preço, que tem atingido até $242 \%$ do custo da matéria-prima, quando os consumidores pretendem pagar até $50 \%$ a mais (DURIGAN \& DURIGAN, 2007; SATO et al., 2007). O crescimento do consumo dos produtos MP está entre 10 e $20 \%$ ao ano no Brasil, o que não é diferente do observado em países da Europa, tais como: Espanha e Portugal (DURIGAN \& DURIGAN, 2007). O sucesso e a expansão das vendas desses produtos dependerão do contínuo marketing sobre sua qualidade e de mais pesquisas científicas para o desenvolvimento dessa tecnologia.

O abacaxi é fruta tipicamente tropical, de difícil manuseio para o consumidor, sendo uma das mais indicadas para o processamento mínimo, mas com vida útil muito reduzida após o processo, devido, principalmente, à perda da firmeza. Para a preservação dessa característica, diversos trabalhos utilizando sais de cálcio foram realizados para abacaxi MP (ANTONIOLLI et al., 2003), abacaxi íntegro (PINHEIRO et al., 2005), melão cantaloupe (LUNA-GUZMÁN et al., 1999) e melão 'honeydew' (SAFTNER et al., 2003).

A firmeza tem sido expressa utilizando-se de inúmeros índices, tais como: energia de deformação (LUNA-GUZMÁN \& BARRET, 2000), força de ruptura (ANINO et al., 2006), força máxima (PINHEIRO et al., 2005; ANTONIOLLI et al., 2003) e força de cisalhamento (SAFTER et al., 2003). No entanto, não são apresentados dados de variabilidade das medidas ou mesmo discussões sobre os procedimentos empregados. Em alguns casos, esses procedimentos não são explicitados com detalhes, sugerindo serem implicitamente conhecidos.

Devido aos escassos estudos disponíveis relativos à estrutura física do abacaxi MP, este trabalho teve como objetivo geral avaliar a ação do cálcio na firmeza do abacaxi cortado em fatias, como indicador do prolongamento de sua vida útil. Os objetivos específicos foram verificar a variação temporal do índice de firmeza de fatias de abacaxi 'Smooth Cayenne' minimamente processado, quando tratadas com diferentes sais de cálcio (cloreto, sulfato e lactato), nas concentrações de $1 \%$ e $3 \%$; identificar a fonte e a concentração de cálcio mais indicada para a conservação das fatias de abacaxi, e definir índice de firmeza mais adequado para avaliar variações na firmeza das fatias de abacaxi minimamente processado.

\section{MATERIAL E MÉTODOS}

\section{Matéria-prima e processamento mínimo}

Cerca de 50 frutos de abacaxizeiro 'Smooth Cayenne', produzidos na região de Guaracaí -SP, foram obtidos no CEASA - Campinas e transportados ao Laboratório de Tecnologia Pós-Colheita, da Faculdade de Engenharia Agrícola - FEAGRI/UNICAMP, onde frutos íntegros foram selecionados e classificados quanto ao tamanho e coloração da casca. Seguiu-se a classificação, segundo norma do Programa Brasileiro para a Melhoria dos Padrões Comerciais e Embalagens de Hortigranjeiros da CEAGESP (2000), resultando em frutos do Grupo de Polpa Amarela, Classe 5 (maior que 2,1 até 2,5 kg) e ao Subgrupo Cor da Casca Pintada (centro dos frutilhos amarelo).

Uma vez selecionados, os frutos foram lavados sob água corrente e sanitizados por imersão em solução de hipoclorito de sódio a $200 \mathrm{mg} \mathrm{L}^{-1}$ por $15 \mathrm{~min}$. Após drenagem da solução, foram armazenados em câmara refrigerada a $10{ }^{\circ} \mathrm{C} \pm 1{ }^{\circ} \mathrm{C}$, por período não inferior a 20 horas, para diminuir a temperatura da polpa antes do processamento, e reduzir a atividade metabólica. No dia seguinte, para o processamento, os frutos foram retirados da câmara, levados a uma sala climatizada com temperatura de $15^{\circ} \mathrm{C} \pm 2{ }^{\circ} \mathrm{C}$, descoroados e descascados manualmente (com facas afiadas), 
cortados em rodelas com espessura de aproximadamente $15 \mathrm{~mm}$, sendo o miolo retirado com um anel vazador de aço inoxidável com $20 \mathrm{~mm}$ de diâmetro interno. Em seguida, as rodelas foram imersas durante 5 min em soluções de cloreto de cálcio, sulfato de cálcio e lactato de cálcio, nas concentrações de $1 \%$ e $3 \%$.

Todos os sais foram dissolvidos e diluídos em água destilada, em temperatura ambiente, na proporção de $10 \mathrm{~g}$ do sal para $1 \mathrm{~L}$ de água, nas concentrações de $1 \%$, e $30 \mathrm{~g}$ do sal para $1 \mathrm{~L}$ de água, nas concentrações de 3\%. O tratamento-testemunha consistiu na imersão das rodelas em água destilada, por $5 \mathrm{~min}$. Após a aplicação dos tratamentos, as rodelas foram colocadas horizontalmente sob uma grade para a drenagem do líquido excedente, durante aproximadamente $3 \mathrm{~min}$. Todas as fontes de cálcio utilizadas são aditivos alimentares, testados toxicologicamente pelo Joint FAO/WHO Expert Committee on Food Additives - JECFA, e agentes de firmeza, de acordo com ANVISA (2001).

Os utensílios utilizados (tábua de corte, facas com lâminas afiadas, anel vazador para retirada do miolo, grades de drenagem e recipientes), as bancadas de apoio e a sala de processamento foram previamente sanitizadas com solução de hipoclorito de sódio a $200 \mathrm{mg} \mathrm{L}^{-1}$.

As rodelas de abacaxi minimamente processadas com os devidos tratamentos foram acondicionadas em bandejas plásticas de Polietileno Tereftalato (PET), devidamente identificadas, com tampas de encaixe e capacidade de $750 \mathrm{~mL}$ (duas rodelas por bandeja), em triplicata, e armazenadas a $5{ }^{\circ} \mathrm{C} \pm 1{ }^{\circ} \mathrm{C}$ durante 9 dias. As avaliações de qualidade foram feitas por meio de ensaios mecânicos de penetração, medidas de $\mathrm{pH}$ e sólidos solúveis totais (SST) nos dias 0 (apenas para a testemunha), 3; 5 e 7. No dia 9, não foi possível realizar as avaliações de penetração, pois as fatias de abacaxi já apresentavam aspecto bastante degradado (escurecimento acentuado e perda de água). As análises de $\mathrm{pH}$ e SST foram realizadas nesse dia.

\section{Delineamento experimental}

O experimento foi inteiramente casualizado, com sete tratamentos distintos, sendo três soluções de cálcio (cloreto, sulfato e lactato), com duas concentrações (1\% e 3\%) para cada sal, mais a testemunha, e três datas (firmeza) ou quatro datas (pH e SST) de leituras para avaliação. Prepararam-se triplicatas para cada tratamento, utilizando-se de 18 repetições para avaliação da firmeza (seis ensaios em cada fatia).

Para as comparações estatísticas, utilizou-se do software SAS System for Windows 6.11 e a planilha eletrônica Excel ${ }^{\circledR}$ - Windows ${ }^{\circledR} 2000$ para agrupamento organizacional e descritivo do trabalho. Para as comparações múltiplas de médias, foram utilizados análise de variância e teste de Tukey, a 5\% de significância, e Teste de Dunnett para comparar determinados tratamentos com a testemunha (NOGUEIRA, 1992).

\section{Análises físico-químicas}

Medidas de $\mathrm{pH}$ : foi medido diretamente por potenciometria (pHmetro analyser), consistindo na imersão do eletrodo na amostra triturada e homogeneizada, segundo procedimento descrito por CARVALHO et al. (1990).

Sólidos Solúveis Totais (SST): o teor de SST foi determinado por refratometria (Abbe Refractometer, modelo LAMBDA 2WAJ, ATTO Instruments Company - Hong Kong), colocandose uma gota da amostra no visor do aparelho e fazendo-se leituras diretas, sendo os resultados expressos em ${ }^{\circ}$ Brix (CARVALHO et al., 1990).

Firmeza: a firmeza da polpa foi determinada por meio de ensaios de penetração, utilizando-se de máquina universal de ensaios (The Ottowa Texture Measuring System, Canners Machinery Limited, Simcoe, Ontário - Canadá), do Laboratório de Propriedades Físicas e Mecânicas de Materiais Biológicos da FEAGRI. Foram utilizadas duas ponteiras distintas, uma cilíndrica (a mais comum) com $8 \mathrm{~mm}$ de diâmetro (ponteira 1) e outra em forma de anel vazador cilíndrico, com bordas afiadas, de diâmetro externo de 15,8 $\mathrm{mm}$ e interno de 13,5 $\mathrm{mm}$ (ponteira 2). Na primeira, a 
interação com o produto é potencialmente mais localizada e pode ser afetada pela distribuição local das fibras, ora concentrando os esforços sobre um feixe delas, ora afastando os feixes durante a penetração, ou uma combinação delas. Na segunda ponteira, não-convencional, a interação ocorre ao longo do fio de corte, numa extensão maior que na primeira, representando parcela mais significativa, solicitando os tecidos à compressão e facilitando o corte (cisalhamento) devido à borda afiada. A geometria dessa ponteira sugere menor probabilidade de afastamento das fibras durante a penetração.

O procedimento de ensaio consistiu em colocar cada fatia de abacaxi sobre prato plano, rígido e horizontal da máquina universal, realizando penetrações em três pontos de cada fatia, separados de 120 graus e localizados na circunferência média da coroa circular, à taxa de deformação de $1 \mathrm{~mm} \mathrm{~s}^{-1}$, sendo registradas curvas de força-deformação. Duas fatias de aproximadamente $300 \mathrm{~g}$ de cada embalagem foram utilizadas, totalizando seis ensaios por bandeja para cada uma das ponteiras, com total de 18 ensaios por tratamento (três repetições). Nas análises das curvas obtidas com a ponteira 1, a Força Máxima e a Energia de Deformação foram utilizadas como Índices de Firmeza. Para os ensaios com a ponteira 2, os İ́ndices de Firmeza utilizados foram a Inclinação da Curva, no primeiro trecho linear, e a Energia de Deformação. Nesse caso, a força máxima como índice de firmeza foi substituída pela inclinação da curva, pois uma inspeção nas curvas revelou alta variabilidade nos valores de força máxima.

A identificação do primeiro trecho linear, que ocorre logo após a acomodação característica do início do ensaio, onde pequenas forças correspondem a grandes deformações, foi realizada com o auxílio de uma régua. Identificado o trecho, tomaram-se as coordenadas de dois pontos extremos, obtendo-se a sua inclinação expressa em $\mathrm{N} \mathrm{mm}^{-1}$. Para ambas as ponteiras, a obtenção da energia de deformação ocorreu por meio do cálculo da área sob a curva, em intervalos de $0,01 \mathrm{~mm}$, até a deformação de $5 \mathrm{~mm}$, utilizando-se do Método dos Trapézios. Esse índice integra as relações forçadeformação expressando o valor da energia de deformação até a deformação considerada e, conseqüentemente, possui maior potencial para melhor representar o comportamento mecânico do que a força máxima. Os índices de firmeza obtidos foram utilizados para avaliar temporalmente o efeito dos vários tratamentos e, também, foram comparados entre si quanto à variabilidade e à resolução, em busca de melhor procedimento para a obtenção do índice de firmeza para o abacaxi. Essa comparação é pertinente, pois não existe procedimento padronizado para avaliar a firmeza.

\section{RESULTADOS E DISCUSSÃO}

\section{Medidas de pH e SST}

Apresentam-se, na Tabela 1, os valores médios das medidas de $\mathrm{pH}$ e SST, além da comparação de médias entre os tratamentos para todo o período de armazenamento. A testemunha, no dia 0 , apresentou os valores de $\mathrm{pH}$ e SST de 2,95 e 10,42 ${ }^{\circ}$ Brix, respectivamente. Para o parâmetro $\mathrm{pH}$, não houve diferença significativa (Tukey, $\mathrm{p}<0,05$ ) entre os tratamentos em nenhum dos dias avaliados. Nota-se ligeiro aumento nos valores do $\mathrm{pH}$, nos 9 dias de armazenamento, inclusive mostrando que ocorreu diferença estatística ao longo do tempo, estando esses resultados de acordo com GONÇALVES (2000), que relatou que os valores de $\mathrm{pH}$ de abacaxi se enquadram na faixa de 3,4 a 3,9 a partir do $5^{\circ}$ dia de armazenamento. Portanto, constata-se que os sais de cálcio utilizados não influenciaram nos valores médios de $\mathrm{pH}$.

Para os SST, não ocorreram diferenças significativas, a 5\% de probabilidade, para o $3^{\mathrm{o}}$ e o $7^{\mathrm{o}}$ dia de armazenamento, mas, para os dias 5 e 9, verificou-se a ocorrência dessas diferenças, sem porém evidenciar padrão de comportamento (Tabela 1). Essas variações de SST devem-se, provavelmente, à heterogeneidade do produto e não aos tratamentos de cálcio aplicados, mas ainda estão dentro dos limites aceitáveis pelo consumidor, que é entre 9,0 e $12,75^{\circ}$ Brix, segundo GONÇALVES (2000). No $5^{\underline{0}}$ dia, houve diferenças significativas entre os tratamentos, e o tratamento cloreto 3\% apresentou menor valor de SST, diferindo significativamente dos demais tratamentos, com exceção do lactato $1 \%$, do cloreto $1 \%$ e da testemunha. Para o $9^{-}$dia de 
armazenamento, o tratamento 6 (lactato 1\%), com a menor média, diferiu significativamente dos tratamentos 1; 2; 4 e 7. As modificações de SST com o tempo de armazenamento não apresentaram padrão consistente de alteração.

TABELA 1. Valores médios de $\mathrm{pH}$ e SST ( ${ }^{\circ}$ Brix) de fatias de abacaxi MP, tratadas com diferentes sais de cálcio, durante armazenamento. Mean values of $\mathbf{p H}$ and Total Soluble Solids $\left({ }^{0}\right.$ Brix) during storage of minimally processed pineapple slices treated with different calcium salts.

\begin{tabular}{lcccc}
\hline & \multicolumn{4}{c}{ DH } \\
\cline { 2 - 5 } Tratamentos & \multicolumn{4}{c}{ Dias de Armazenamento } \\
\cline { 2 - 5 } & $2,97 \mathrm{aA}$ & $3,48 \mathrm{aB}$ & $3,48 \mathrm{aB}$ & $3,68 \mathrm{aC}$ \\
\hline 1. Testemunha & $2,94 \mathrm{aA}$ & $3,44 \mathrm{aB}$ & $3,43 \mathrm{aB}$ & $3,56 \mathrm{aC}$ \\
2. Cloreto 1\% & $2,93 \mathrm{aA}$ & $3,41 \mathrm{aB}$ & $3,47 \mathrm{aB}$ & $3,44 \mathrm{aB}$ \\
3. Cloreto 3\% & $3,04 \mathrm{aA}$ & $3,22 \mathrm{aB}$ & $3,30 \mathrm{aB}$ & $3,78 \mathrm{aC}$ \\
4. Sulfato 1\% & $3,13 \mathrm{aA}$ & $3,59 \mathrm{aBC}$ & $3,52 \mathrm{aB}$ & $3,71 \mathrm{aC}$ \\
5. Sulfato 3\% & $3,04 \mathrm{aA}$ & $3,14 \mathrm{aA}$ & $3,53 \mathrm{aB}$ & $3,74 \mathrm{aC}$ \\
6. Lactato 1\% & $3,31 \mathrm{aA}$ & $3,29 \mathrm{aA}$ & $3,73 \mathrm{aB}$ & $3,91 \mathrm{aC}$ \\
7. Lactato 3\% & \multicolumn{5}{c}{ SST } \\
\hline & \multicolumn{5}{c}{ Dias de Armazenamento } \\
Tratamentos & $11,50 \mathrm{aA}$ & $10,58 \mathrm{abA}$ & $12,25 \mathrm{aA}$ & $11,25 \mathrm{aA}$ \\
1. Testemunha & $11,25 \mathrm{aA}$ & $10,67 \mathrm{abA}$ & $10,67 \mathrm{aA}$ & $11,25 \mathrm{aA}$ \\
2. Cloreto 1\% & $12,00 \mathrm{aA}$ & $9,25 \mathrm{bB}$ & $12,42 \mathrm{aA}$ & $10,42 \mathrm{abB}$ \\
3. Cloreto 3\% & $11,58 \mathrm{aA}$ & $11,67 \mathrm{aA}$ & $11,42 \mathrm{aA}$ & $11,42 \mathrm{aA}$ \\
4. Sulfato 1\% & $12,00 \mathrm{aA}$ & $11,50 \mathrm{aA}$ & $12,08 \mathrm{aA}$ & $10,75 \mathrm{abA}$ \\
5. Sulfato 3\% & $11,08 \mathrm{aA}$ & $10,58 \mathrm{abAB}$ & $10,58 \mathrm{aAB}$ & $8,92 \mathrm{bB}$ \\
6. Lactato 1\% & $12,75 \mathrm{aA}$ & $11,92 \mathrm{aA}$ & $11,67 \mathrm{aA}$ \\
7. Lactato 3\% & $11,75 \mathrm{aA}$ & \multicolumn{4}{c}{$7 \%$} \\
\hline
\end{tabular}

Valores acompanhados com mesma letra minúscula nas colunas não diferem significativamente (Tukey, $\mathrm{p}<, 05)$. Letras maiúsculas correspondem à comparação na horizontal, entre dias.

\section{Índices de firmeza empregando a ponteira 1 (cilíndrica)}

\section{Força máxima}

Na Tabela 2, são apresentados os valores médios do índice de firmeza expressos pela força máxima e respectivos coeficientes de variação para os tratamentos considerados. $\mathrm{O}$ valor médio do índice de firmeza para o tratamento-testemunha, no dia 0 , foi de $10,128 \mathrm{~N}$ (coeficiente de variação de $24,48 \%$ ).

Para o dia 3, o teste de Tukey $(\mathrm{p}<0,05)$ indicou o tratamento 2 como o único que diferiu significativamente da testemunha. No entanto, o teste de Dunnett mostrou que os tratamentos 2 e 6 (cloreto $1 \%$ e lactato $1 \%$ ), marcados com sombreado, apresentaram diferença significativa em relação à testemunha. No dia 5 , ambos os testes de comparação revelaram diferenças significativas entre os tratamentos 4 e 5 (sulfato $1 \%$ e $3 \%$ ) e a testemunha. Para o sétimo dia de armazenamento, todos os tratamentos tiveram desempenho superior, e somente o tratamento 3 (cloreto 3\%) apresentou índice de firmeza médio igual ao da testemunha. $\mathrm{O}$ tratamento 5 (sulfato 3\%), apesar de apresentar o maior índice médio, não diferiu significativamente dos demais, com exceção do tratamento 3. Os testes de Tukey e de Dunnet, para esse dia, evidenciaram os mesmos resultados. 
TABELA 2. Valores médios da força máxima $(\mathrm{N})$ para fatias de abacaxi MP, tratadas com diferentes sais de cálcio, ao longo do armazenamento, utilizando-se a ponteira 1.

Maximum force $(\mathrm{N})$ mean values of minimally processed pineapple slices treated with different calcium salts, using indenter 1.

\begin{tabular}{lcccccc}
\hline \multirow{2}{*}{ Tratamentos } & \multicolumn{7}{c}{ Dias de Armazenamento } \\
\cline { 2 - 7 } & \multicolumn{7}{c}{ C.V.* } & 5 & C.V.* & 7 & C.V. $^{*}$ \\
\hline 1. Testemunha & $10,211 \mathrm{bA}$ & 28,91 & $9,930 \mathrm{bA}$ & 17,77 & $9,501 \mathrm{cA}$ & 21,39 \\
2. Cloreto 1\% & $12,894 \mathrm{aA}$ & 19,26 & $12,110 \mathrm{abA}$ & 18,50 & $12,275 \mathrm{abA}$ & 19,46 \\
3. Cloreto 3\% & $10,665 \mathrm{abA}$ & 24,23 & $10,541 \mathrm{abA}$ & 18,34 & $10,698 \mathrm{bcA}$ & 18,52 \\
4. Sulfato 1\% & $10,360 \mathrm{bB}$ & 23,24 & $13,042 \mathrm{aA}$ & 29,49 & $11,817 \mathrm{abAB}$ & 15,74 \\
5. Sulfato 3\% & $11,887 \mathrm{abA}$ & 17,27 & $12,795 \mathrm{aA}$ & 26,96 & $13,917 \mathrm{aA}$ & 19,21 \\
6. Lactato 1\% & $12,398 \mathrm{abA}$ & 15,93 & $11,317 \mathrm{abA}$ & 21,08 & $12,357 \mathrm{abA}$ & 18,58 \\
7. Lactato 3\% & $11,441 \mathrm{abA}$ & 20,05 & $11,235 \mathrm{abA}$ & 25,49 & $12,093 \mathrm{abA}$ & 18,54 \\
\hline
\end{tabular}

Valores acompanhados com mesma letra minúscula nas colunas não são diferentes (Tukey, $\mathrm{p}<0,05$ ). Letras maiúsculas correspondem à comparação na horizontal, entre dias. Valores destacados com sombreado diferem significativamente da testemunha (Dunnett, $\mathrm{p}<0,05)$. *Coeficiente de Variação em \%.

Assim, para os três dias analisados, o efeito do cálcio na manutenção do índice de firmeza foi significativo, principalmente no sétimo dia, em que todos, com exceção do tratamento 3 , apresentaram índice de firmeza superior ao da testemunha. Os tratamentos $2 ; 4 ; 5$ e 6 (cloreto $1 \%$, sulfato $1 \%$ e $3 \%$ e lactato $1 \%$ ) destacaram-se dos demais, pois apresentaram diferenças significativas em relação à testemunha para o teste de Dunnett em, pelo menos, dois dias de avaliações. Da comparação de médias (Tukey, $\mathrm{p}<0,05$ ), para cada tratamento, ao longo dos dias (letras maiúsculas, na horizontal), observa-se que a presença do cálcio manteve as fatias com a mesma firmeza média durante o período de armazenamento. Observa-se, também (Tabela 2), que alguns valores do C.V. são relativamente altos, próximo de 30\%, afetando as comparações e mostrando que a utilização dos sais de cálcio não minimiza esse comportamento.

\section{Energia de deformação}

Análise semelhante foi realizada a partir da comparação de média dos índices de firmeza baseados na energia de deformação, que são apresentadas na Tabela 3. O valor médio para o tratamento-testemunha, no dia 0 , é 39,212 N mm, com coeficiente de variação de 20,34\%.

TABELA 3. Valores médios de firmeza ( $\mathrm{N} \mathrm{mm}$ ), baseada na energia de deformação de abacaxi MP, tratado com sais de cálcio, ao longo do armazenamento, utilizando a ponteira 1 . Firmness mean values $(\mathrm{N} \mathbf{~ m m})$ based in deformation energy, during storage of minimally processed pineapple slices treated with different calcium salts, using indenter 1.

\begin{tabular}{lcccccc}
\hline \multirow{2}{*}{ Tratamentos } & \multicolumn{7}{c}{ Dia de Armazenamento } \\
\cline { 2 - 7 } & 3 & C.V.* & 5 & C.V. & 7 & C.V. \\
\hline 1. Testemunha & $35,214 \mathrm{bA}$ & 32,49 & $34,091 \mathrm{bA}$ & 26,24 & $32,854 \mathrm{cA}$ & 17,64 \\
2. Cloreto 1\% & $44,564 \mathrm{aA}$ & 16,85 & $39,329 \mathrm{abB}$ & 17,03 & $42,172 \mathrm{abA}$ & 16,57 \\
3. Cloreto 3\% & $36,962 \mathrm{abA}$ & 19,13 & $35,254 \mathrm{bA}$ & 19,11 & $35,967 \mathrm{bcA}$ & 18,56 \\
4. Sulfato 1\% & $34,275 \mathrm{bA}$ & 22,66 & $47,936 \mathrm{aB}$ & 37,09 & $39,419 \mathrm{bcA}$ & 14,68 \\
5. Sulfato 3\% & $42,661 \mathrm{abB}$ & 21,94 & $43,503 \mathrm{abB}$ & 25,63 & $47,459 \mathrm{aA}$ & 15,10 \\
6. Lactato 1\% & $44,011 \mathrm{aA}$ & 17,65 & $39,559 \mathrm{abB}$ & 21,26 & $41,799 \mathrm{abB}$ & 18,39 \\
7. Lactato 3\% & $38,499 \mathrm{abA}$ & 20,79 & $34,869 \mathrm{bB}$ & 27,88 & $38,921 \mathrm{bcA}$ & 21,42 \\
\hline
\end{tabular}

Valores acompanhados com mesma letra minúscula nas colunas não são diferentes (Tukey, $\mathrm{p}<0,05)$. Letras maiúsculas correspondem à comparação na horizontal, entre dias. Valores destacados com sombreado diferem significativamente da testemunha (Dunnett, $\mathrm{p}<0,05)$. *Coeficiente de Variação em \%. 
No dia 3, pôde-se constatar que os tratamentos 2 e 6 (cloreto $1 \%$ e lactato $1 \%$ ) diferiram significativamente da testemunha e do tratamento 4 (sulfato 1\%) (Tukey, $\mathrm{p}<0,05$ ). Os tratamentos 2; 5 e 6 (cloreto $1 \%$, sulfato $3 \%$ e lactato $1 \%$ ) apresentaram diferença significativa em relação à testemunha, por meio do teste de Dunnet. Para o dia 5, o tratamento 4 (sulfato 1\%) diferiu significativamente (Tukey, $\mathrm{p}<0,05$ ) da testemunha e dos tratamentos 3 e 7 (cloreto 3\% e lactato $3 \%$ ), e os tratamentos 4 e 5 (sulfato $1 \%$ e $3 \%$ ) apresentaram diferenças significativas em relação à testemunha (Dunnet). Já no dia 7, o tratamento 5 (sulfato 3\%) diferiu significativamente dos tratamentos 3; 4 e 7 (cloreto $3 \%$, sulfato $1 \%$ e lactato $3 \%$ ) e da testemunha (Tukey, $\mathrm{p}<0,05$ ), enquanto os tratamentos $2 ; 5$ e 6 (cloreto $1 \%$, sulfato $3 \%$ e lactato $1 \%$ ) apresentaram diferenças significativas em relação à testemunha, por meio do teste de Dunnet.

Analisando-se as variações ao longo dos dias, as fatias-testemunha não apresentaram diferença no índice de firmeza médio entre o terceiro e o último dia, o mesmo ocorrendo para os demais tratamentos, com exceção dos tratamentos 5 e 6 . Diante desses resultados, pode-se afirmar que houve incremento no valor dos índices médios de firmeza, nas fatias tratadas com cálcio, e os tratamentos 2; 5 e 6 (cloreto $1 \%$, sulfato 3\% e lactato 1\%) destacaram-se dos demais, pois apresentaram diferenças significativas em relação à testemunha em, pelo menos, dois dias de avaliação, sendo o tratamento com sulfato de cálcio 3\% o que apresentou, no último dia, índice de textura $44,45 \%$ maior que o da testemunha.

\section{Desempenho dos índices de firmeza para a ponteira 1}

Valores médios globais dos coeficientes de variação, apresentados nas Tabelas 2 e 3, calculados para os dias 3; 5 e 7 , apresentaram valores de $21,46 \%, 23,70 \%$ e $18,13 \%$, respectivamente. $\mathrm{O}$ último valor foi significativamente diferente dos demais (Tukey, $\mathrm{p}<0,05$ ), indicando diminuição na variabilidade das propriedades mecânicas das fatias para o último dia de armazenamento. Os valores médios de todos os coeficientes de variação apresentados nas Tabelas 2 e 3, para os índices baseados na força máxima e na energia de deformação, de $20,85 \%$ e $21,34 \%$, respectivamente, não são significativamente diferentes (Tukey, $\mathrm{p}<0,05)$ e indicam que não houve ganhos quanto à variabilidade entre utilizar um índice ou outro.

\section{Índices de firmeza empregando a ponteira 2 (anel vazador)}

\section{Inclinação da curva}

Os resultados de firmeza expressos por meio da inclinação do primeiro trecho linear da curva força-deformação e da energia de deformação são analisados para a ponteira 2, cujos valores médios dos índices de firmeza baseados na inclinação da curva são apresentados na Tabela 4. $\mathrm{O}$ valor médio para o tratamento-testemunha, no dia 0 , é 7,705 N, com C.V. de 27,29\%.

Para o $3^{\mathrm{o}}$ dia de armazenamento, o tratamento 5 (sulfato $3 \%$ ) diferiu significativamente (Tukey, $\mathrm{p}<0,05$ ) da testemunha e dos tratamentos 3 e 4 (cloreto $3 \%$ e sulfato $1 \%$ ). Os tratamentos 2 e 5 (cloreto $1 \%$ e sulfato $3 \%$ ) apresentaram diferença significativa em relação à testemunha por meio do teste de Dunnet. No dia 5, o tratamento 5 (sulfato 3\%) diferiu significativamente da testemunha e do tratamento 2 (cloreto $1 \%$ ), e o tratamento 2 também diferiu do tratamento 4 (sulfato $1 \%$ ) (Tukey, $\mathrm{p}<0,05$ ). Os tratamentos 4 e 5 (sulfato $1 \%$ e $3 \%$ ) apresentaram diferenças significativas em relação à testemunha (Dunnet). Para o dia 7 , os tratamentos 4 e 5 (sulfato $1 \%$ e $3 \%$ ) diferiram significativamente da testemunha (Tukey, $p<0,05$ ) e os tratamentos 4; 5 e 6 (sulfato $1 \%$ e $3 \%$ e lactato $1 \%$ ) apresentaram diferenças significativas em relação à testemunha (Dunnett).

As comparações de médias para cada tratamento, entre o terceiro e sétimo dias, não apresentaram diferenças significativas para nenhum dos tratamentos, inclusive para a testemunha, indicando que o índice de firmeza médio não foi afetado pelo tempo de armazenamento de sete dias ou que a metodologia não foi capaz de discriminar as possíveis diferenças. Pode-se afirmar que os tratamentos $2 ; 4 ; 5$ e 6 (cloreto $1 \%$, sulfato $1 \%$ e $3 \%$ e lactato $1 \%$ ) destacaram-se dos demais, pois apresentaram diferenças significativas em relação à testemunha, para o teste de Dunnett. 
TABELA 4. Valores médios de firmeza $\left(\mathrm{N} \mathrm{mm}^{-1}\right)$, baseada na inclinação da curva forçadeformação de abacaxi MP, tratado com sais de cálcio, ao longo do armazenamento, utilizando a ponteira 2. Firmness mean values $\left(\mathrm{N} \mathrm{mm}^{-1}\right)$ based in the slope of the force-deformation curve, during storage of minimally processed pineapple slices treated with different calcium salts, using indenter 2.

\begin{tabular}{lllllll}
\hline \multirow{2}{*}{ Tratamentos } & \multicolumn{7}{c}{ Dia de Armazenamento } \\
\cline { 2 - 7 } & 3 & C.V. & \multicolumn{1}{c}{5} & C.V. & 7 & C.V. \\
\hline 1. Testemunha & $6,520 \mathrm{cA}$ & 33,48 & $6,789 \mathrm{bcA}$ & 20,98 & $6,733 \mathrm{bA}$ & 12,23 \\
2. Cloreto 1\% & $8,575 \mathrm{abA}$ & 22,54 & $6,728 \mathrm{cB}$ & 23,14 & $7,520 \mathrm{abAB}$ & 22,21 \\
3. Cloreto 3\% & $7,151 \mathrm{bcA}$ & 26,82 & $7,022 \mathrm{abcA}$ & 22,89 & $6,978 \mathrm{abA}$ & 22,70 \\
4. Sulfato 1\% & $7,188 \mathrm{bcA}$ & 29,74 & $8,555 \mathrm{abA}$ & 24,61 & $8,436 \mathrm{aA}$ & 26,63 \\
5. Sulfato 3\% & $9,634 \mathrm{aA}$ & 14,51 & $8,754 \mathrm{aA}$ & 27,33 & $8,513 \mathrm{aA}$ & 17,38 \\
6. Lactato 1\% & $8,109 \mathrm{abcA}$ & 18,56 & $7,436 \mathrm{abcA}$ & 18,07 & $8,371 \mathrm{abA}$ & 21,43 \\
7. Lactato 3\% & $7,750 \mathrm{abcA}$ & 26,67 & $7,319 \mathrm{abcA}$ & 27,89 & $7,023 \mathrm{abA}$ & 26,51 \\
\hline
\end{tabular}

Valores acompanhados com mesma letra minúscula nas colunas não são diferentes (Tukey, $\mathrm{p}<0,05)$. Letras maiúsculas correspondem à comparação na horizontal, entre dias. Valores destacados com sombreado diferem significativamente da testemunha (Dunnett, p<0,05). *Coeficiente de Variação em \%.

\section{Energia de deformação}

Valores médios do índice de firmeza ao longo do armazenamento, para fatias de abacaxi MP, tratadas com diferentes sais de cálcio, expressos por meio da energia de deformação, extraída da curva força-deformação até $5 \mathrm{~mm}$ de deformação, são apresentados na Tabela 5 . O valor médio para o tratamento-testemunha, no dia 0 , é $57,339 \mathrm{~N} \mathrm{~mm}$, com C.V. de $18,84 \%$.

TABELA 5. Valores médios de firmeza $(\mathrm{N} \mathrm{mm})$, baseados na energia de deformação, para fatias de abacaxi MP tratadas com diferentes sais de cálcio, ao longo do armazenamento, utilizando-se a ponteira 2. Firmness mean values $(\mathbf{N} \mathbf{~ m m})$ based in deformation energy, during storage of minimally processed pineapple slices treated with different calcium salts, using indenter 2.

\begin{tabular}{lcclccc}
\hline \multirow{2}{*}{ Tratamentos } & \multicolumn{7}{c}{ Dia de Armazenamento } \\
\cline { 2 - 7 } & \multicolumn{1}{c}{3} & C.V.* & 5 & C.V. & 7 & C.V. \\
\hline 1. Testemunha & $49,932 \mathrm{bA}$ & 30,05 & $55,558 \mathrm{abcA}$ & 21,35 & $54,368 \mathrm{bA}$ & 13,63 \\
2. Cloreto 1\% & $62,501 \mathrm{abA}$ & 32,99 & $56,427 \mathrm{abcAB}$ & 20,13 & $54,539 \mathrm{bB}$ & 24,61 \\
3. Cloreto 3\% & $53,171 \mathrm{abA}$ & 16,71 & $53,839 \mathrm{bc} \mathrm{A}$ & 18,64 & $55,458 \mathrm{bA}$ & 18,18 \\
4. Sulfato 1\% & $57,414 \mathrm{abA}$ & 29,81 & $63,734 \mathrm{abA}$ & 19,52 & $61,592 \mathrm{abA}$ & 26,31 \\
5. Sulfato 3\% & $66,076 \mathrm{aA}$ & 13,46 & $66,940 \mathrm{aA}$ & 16,77 & $71,157 \mathrm{aA}$ & 18,39 \\
6. Lactato 1\% & $65,346 \mathrm{aA}$ & 15,56 & $55,236 \mathrm{abcB}$ & 18,39 & $59,881 \mathrm{abAB}$ & 17,85 \\
7. Lactato 3\% & $56,279 \mathrm{abA}$ & 21,84 & $49,746 \mathrm{cA}$ & 32,24 & $50,951 \mathrm{bA}$ & 29,40 \\
\hline
\end{tabular}

Valores acompanhados com mesma letra minúscula nas colunas não são diferentes (Tukey, $\mathrm{p}<0,05)$. Letras maiúsculas correspondem à comparação na horizontal, entre dias. Valores destacados com sombreado diferem significativamente da testemunha (Dunnett, $\mathrm{p}<0,05)$. * Coeficiente de Variação em \%.

Para o dia 3, os tratamentos 5 e 6 (sulfato 3\% e lactato 1\%) diferiram significativamente da testemunha (Tukey, $\mathrm{p}<0,05$ ), e os tratamentos 2 ; 5 e 6 (cloreto $1 \%$, sulfato $3 \%$ e lactato $1 \%$ ) apresentaram diferenças significativas em relação à testemunha (Dunnett). Para o dia 5, o tratamento 5 (sulfato 3\%) diferiu significativamente dos tratamentos 3 e 7 (cloreto 3\% e lactato 3\%) (Tukey, $\mathrm{p}<0,05)$ e apresentou diferença significativa em relação à testemunha, para o teste de Dunnett. No dia 7, apenas o tratamento 5 (sulfato 3\%) diferiu significativamente da testemunha (Tukey, $\mathrm{p}<0,05$ ), coincidindo com o resultado do teste de Dunnett. Observaram-se diferenças significativas entre a testemunha e os tratamentos, nas três datas de avaliação, sendo o tratamento com sulfato de cálcio 3\% o que mais se destacou. Os tratamentos $2 ; 5$ e 6 (cloreto $1 \%$, sulfato 3\% e lactato $1 \%$ ) também se destacaram dos demais, pois apresentaram diferenças significativas em 
relação à testemunha, mas somente o tratamento 5 (sulfato 3\%) apresentou diferença significativa (Dunnett) para as três datas de avaliações. Não foram observadas diferenças significativas entre as médias dos índices no primeiro e no último dia de avaliação (Tukey, $p<0,05$ ), exceto para o tratamento 2, que apresentou redução no índice de firmeza. Novamente, esses valores apontam que o tempo de armazenamento não afetou os valores médios dos índices de firmeza.

\section{Desempenho dos índices de firmeza para a ponteira 2}

Valores médios globais dos coeficientes de variação, apresentados nas Tabelas 4 e 5 , calculados para os dias 3; 5 e 7 , apresentaram valores de 23,77\%, 22,28\% e 21,23\%, respectivamente. Apesar de ligeiro decréscimo ao longo do tempo, não apresentam diferenças significativas (Tukey, $\mathrm{p}<0,05$ ) entre si, indicando manutenção na variabilidade das propriedades mecânicas das fatias entre os dias de armazenamento. Os valores médios globais dos coeficientes de variação, média de todos os coeficientes de variação, apresentados nas Tabelas 4 e 5, para os índices baseados na inclinação da curva e energia de deformação, de $23,16 \%$ e $21,71 \%$, respectivamente, não são significativamente diferentes (Tukey, $\mathrm{p}<0,05$ ) e indicam não haver ganhos quanto à variabilidade entre utilizar um índice ou outro.

\section{Desempenho comparativo global dos índices das ponteiras 1 e 2}

Os coeficientes médios de variação globais, incluindo ambos os índices de cada ponteira, de $21,10 \%$ e $22,44 \%$, não são significativamente diferentes (Tukey, $\mathrm{p}<0,05$ ), indicando que a variabilidade dos índices de firmeza fornecida pelas avaliações, por ambas as ponteiras, é semelhante. No entanto, o potencial de discriminação ou resolução dos valores dos índices parece ser maior para a ponteira 1 , pois essa foi capaz de apontar 17 vezes as diferenças entre tratamentos e testemunhas, contra 12 vezes da ponteira 2.

Relatos de aplicação de cálcio em fatias de abacaxi mostram que nem sempre seus efeitos são perceptíveis. PRADO et al. (2000) testaram o efeito do cloreto de cálcio a 1\% em abacaxis 'Smooth Cayenne' minimamente processados e armazenados a $10{ }^{\circ} \mathrm{C}$ por 8 dias e comprovaram, positivamente, o efeito do cálcio na textura do produto. Porém, ANTONIOLLI et al. (2003), estudando os efeitos do cloreto de cálcio ( $1 \%$ e $2 \%)$, na qualidade do abacaxi 'Pérola' minimamente processado e armazenado a $4{ }^{\circ} \mathrm{C}$, verificaram que a utilização de $\mathrm{CaCl}_{2}$ não manteve a firmeza e interferiu negativamente na coloração da polpa dos frutos.

\section{CONCLUSÕES}

Para os tratamentos utilizados, os valores médios de $\mathrm{pH}$ e SST ficaram dentro da faixa recomendada para o consumo, não sendo constatadas diferenças nos seus valores, ao longo do tempo de armazenamento, que possam ser atribuídas ou originadas pela aplicação de cálcio.

Para a variável índice de firmeza, os tratamentos com cloreto de cálcio $1 \%$, sulfato de cálcio $1 \%$ e $3 \%$ e lactato de cálcio $1 \%$ destacaram-se dos demais, pois apresentaram maior número de diferenças significativas em relação à testemunha, durante o armazenamento.

Os índices de firmeza estudados para a ponteira cilíndrica, baseados na força máxima e na energia de deformação, e para a ponteira de anel vazador, baseados na inclinação do primeiro trecho linear da curva força-deformação e na energia de deformação, apresentaram variabilidade semelhante.

A ponteira cilíndrica possui maior potencial de discriminar diferenças na firmeza que o anel vazador, pois apontou número maior de diferenças entre a testemunha e os tratamentos.

\section{REFERÊNCIAS}

ANINO, S.V.; SALVATORI, D.M.; ALZAMORA, S.M. Changes in calcium level and mechanical properties of apple tissue due to impregnation with calcium salts. Food Research International, Amsterdam, v.39, n.2, p.154-64, 2006. 
ANTONIOLLI, L.R.; BENEDETTI, B.C.; SOUZA FILHO, M.S.M. Efeito do cloreto de cálcio na qualidade de abacaxi "Pérola" minimamente processado. Pesquisa Agropecuária Brasileira, Brasília, v.38, n.9, p.1105-10, set. 2003.

ANVISA. AGÊNCIA NACIONAL DE VIGILÂNCIA SANITÁRIA. Resolução RCD $n^{\circ} 12$, de 02 de janeiro de 2001. Disponível em:

http://elegis.anvisa.gov.br/leisref/public/showAct.php?id=144\&word=\#'. Acesso em: 5 set. 2007.

CARVALHO, C.R.L.; MANTOVANI, D.M.B.; CARVALHO, P.R.N.; MORAES, R.M.M.

Análises químicas de alimentos. Campinas: ITAL, 1990. 121 p. Manual Técnico

CEAGESP. COMPANHIA DE ENTREPOSTOS E ARMAZÉNS GERAIS DE SÃO PAULO.

Programa Brasileiro para a Modernização da Horticultura. Folheto de classificação do abacaxi. 2000. Disponível em:

http://www.ceagesp.gov.br/produtor/tecnicas/classific/. Acesso em: 4 dez. 2007.

DURIGAN, J.F.; DURIGAN, M.F.B. Tendências do mercado de produtos minimamente processados. In: SIMPÓSIO BRASILEIRO DE PÓS-COLHEITA DE FRUTAS, HORTALIÇAS E FLORES, 2., 2007, Viçosa. Resumos... Viçosa: UFV, 2007. p.105-7.

GONÇALVES, N.B. Abacaxi: pós-Colheita. Brasília: Embrapa-SCT, 2000. 45 p. (Frutas do Brasil, $5)$.

JECTA. JOINT FAO/WHO EXPERT COMMITTEE ON FOOD ADDITIVES. Disponível em: http://apps3.fao.org. Acesso em: 27 set. 2002.

LUNA-GUZMÁN, I.; BARRET, D.M. Comparison of calcium chloride and calcium lactate effectiveness in maintaining shelf stability and quality of fresh-cut cantaloupe. Postharvest Biology and Technology, Amsterdam, v.19, n.1, p.61-72, 2000.

LUNA-GUZMÁN, I.; CANTWELL, M. A.; BARRET, D.M. Fresh-cut cantaloupe: effect of $\mathrm{CaCl}_{2}$ dips and heat treatments on firmness and metabolic activity. Postharvest Biology and Technology, Amsterdam, v.17, n.3, p.201-13, 1999.

NOGUEIRA, M.C.S. Curso de estatística experimental aplicada à experimentação agronômica. Piracicaba: ESALQ/USP, 1992. 121 p.

PINHEIRO, A.C.M.; VILAS BOAS, E.V.B.; LIMA, L.C. Influência do $\mathrm{CaCl}_{2}$ sobre a qualidade pós-colheita do abacaxi cv. Pérola. Ciência e Tecnologia de Alimentos, Campinas, v.25, n.1, p.32-6, 2005.

PRADO, M.E.T.P.; CHITARRA, A.B.; BONNAS, D.S.; VILAS BOAS, E.V.B. Abacaxi "Smooth Cayenne" minimamente processado. In: ENCONTRO NACIONAL SOBRE PROCESSAMENTO MÍNIMO DE FRUTAS E HORTALIÇAS, 2., 2000, Viçosa. Resumos... Viçosa: UFV, 2000. p.6.

SAFTNER, R.A.; BAI, J.; ABBOTT, J.A.; LEE, Y.S. Sanitary dips with calcium propionate, calcium chloride, or calcium amino acid chelates maintain quality and shelf stability of fresh-cut honeydew chunks. Postharvest Biology and Technology, Amsterdam, v.29, n.3, p.257-69, 2003.

SATO, G.S.; MARTINS, V.A.; BUENO, C.R.F. Análise exploratória do perfil do consumidor de produtos minimamente processados na cidade de São Paulo. Informações Econômicas, São Paulo, v.37, n.6, p.62-71, jun 2007. 